\title{
Factors associated with overactive bladder syndrome in the elderly community: a cross-sectional study
}

\author{
Albênica Paulino dos Santos Bontempo? \\ Aline Teixeira Alves $^{2}$ \\ Gabriela de Sousa Martins' \\ Raquel Henriques Jácomo ${ }^{3}$ \\ Danieli Coeli Malschik ${ }^{4}$ \\ Ruth Losada de Menezes'
}

\section{Abstract}

Objective: to identify risk factors related to overactive bladder syndrome. Method: a crosssectional study was performed with elderly women ( $>60$ years) from the community of Ceilândia, in the Distrito Federal, Brazil, with or without symptoms of OBS, who were evaluated through interviews and questionnaires. The clinical and sociodemographic variables analyzed were: age; body mass index (BMI); parity, schooling, previous abdominal and urogynecologic surgeries, physical activity, smoking, constipation, systemic arterial hypertension $(\mathrm{SAH})$, diabetes mellitus; depression and anxiety. The questionnaires applied were the Overactive Bladder Awareness Tool (OAB-V8), the Geriatric Depression Scale and the Beck Anxiety Scale. Data were analyzed descriptively. Binary logistic regression was used to evaluate the significant associations between the independent variables and the outcome of interest. Risk ratios were calculated for each independent variable with 95\% confidence intervals. Result: A total of 372 volunteers were recruited, 292 of whom were eligible. Of these, 172 were allocated to the case group (58.9\%) and $120(41.1 \%)$ were control subjects. The two groups were homogeneous between one another. There was a high prevalence of OBS in the study population and significant differences for the variables presence of SAH, abdominal surgery and pelvic surgery, with the case group presenting a higher frequency of these events. In multivariate analysis, it was observed that an active sexual life reduces the chance of having OBS by $70.8 \%$, while urogynecologic surgeries increase this risk 3.098 times. Conclusion: In univariate logistic regression analysis, BMI, SAH, a previous history of abdominal and urogynecologic surgery, number of abortions and the presence of symptoms of depression and anxiety, were found to be factors associated with OBS.

\footnotetext{
Universidade de Brasília (UNB), Programa de pós-graduação em Ciências e Tecnologia em saúde. Distrito Federal, Brasília, Brasil.

2 Universidade de Brasília (UNB), Programa de pós-graduação em Ciências da Reabilitação. Distrito Federal, Brasília, Brasil.

3 Universidade de Brasília (UNB), Programa de pós-graduação em Ciências Médicas. Distrito Federal, Brasília, Brasil.

4 Universidade de Brasília (UNB), Faculdade de Ceilândia, Projeto de extensão do Departamento de Fisioterapia. Distrito Federal, Brasília, Brasil.
}

Correspondence

Albênica Paulino dos Santos Bontempo

E-mail: albenica.fisio@gmail.com
Keywords: Urinary Bladder, Overactive. Risk Factors. Elderly. Urinary Incontinence, Urge. 


\section{INTRODUCTION}

Overactive Bladder Syndrome (OBS) is characterized by micturition urgency with or without incontinence, polyuria and nocturia, in the absence of other local pathologies ${ }^{1}$. Its diagnosis is clinical, is evidenced by the presence of the defining symptoms of the condition, and does not involve the use of invasive examinations ${ }^{2}$. The syndrome has a negative impact on quality of life (QOL) ${ }^{3}$ and is associated with high economic costs ${ }^{4}$. It results in social, psychological, emotional, physical and sexual difficulties and is considered a serious health problem which mainly affects elderly women ${ }^{5,6}$.

It is estimated that by 2018 more than 500 million individuals worldwide will suffer from this disorder 7 . North American epidemiological data indicate a prevalence of $16 \%$ among the population of that continent ${ }^{8}$, while for Brazil the estimate is $18 \% 7$. Little is known, however, about the factors associated with OBS and its prevalence among elderly Brazilian women?.

While population-based studies have been conducted in a number of countries to estimate the prevalence and risk factors of OBS, the comparison of results is difficult because of the methodological diversity these works employ and their conflicting results $^{10-12}$. More accurate knowledge on the subject in question is therefore necessary, with risk groups delimited in a more efficient manner.

In view of the above, the present study aims to identify factors associated with the occurrence of OBS in elderly women living in the community.

\section{METHOD}

A cross-sectional study was performed, with the sample group recruited from the activities of the "Escola de Avós" (Grandmother's School) health promotion program, organized by the Health Center for the Elderly of the Primary Health Care Subsecretariat, which takes place in a fire station in the city of Ceilândia, in the Distrito Federal, Brazil. A sample calculation was performed based on the total number of elderly residents in this city $(29,168)$. A sample error of $5 \%$ was considered and $95 \%$ was adopted as the confidence level, resulting in a required sample size of 118 individuals for each group ${ }^{13}$.

The eligibility criteria were: female participants, aged 60 years or older, with or without overactive bladder symptoms, such as: urgency; and/or urge incontinence; and/or polyuria; and/or nocturia; which were evaluated through questionnaires. Older women with a history of neurological diseases (Multiple Sclerosis, Alzheimer's Disease, Vascular Brain Accident, Parkinson's Disease and/ or spinal cord injury); bladder cancer; psychological disturbances or the inability to respond to questionnaires were excluded.

The elderly women underwent an interview to obtain the clinical and sociodemographic variable data. The following information was collected: age; BMI; parity (gestations, vaginal deliveries, cesarean deliveries and abortions), schooling, previous abdominal and urogynecologic surgeries, physical activity, smoking, constipation, systemic arterial hypertension $(\mathrm{SAH})$, diabetes mellitus; depression and anxiety.

They were then divided into two groups: case and control. The groups were divided using the Overactive Bladder Awareness Tool (OAB-V8), an instrument developed to evaluate OBS symptoms. This consists of eight questions related to increased urinary frequency, nocturia, micturition urgency, urinary incontinence, urge incontinence and enuresis, with domains from 0 to 5 , where 0 equals none, 1 almost none, 2 a little, 3 some, 4 a lot and 5 very much. If the sum of the answers is equal to or greater than 8 points there is a probable diagnosis of $\mathrm{OBS}^{14}$.

Following the interview and due completion of the questionnaires, the total points of the questionnaire were used to divide the sample into two groups: one for elderly women with OBS and one for elderly women without OBS, according to the lower urinary tract infection identified by OAB-V8. Women who scored less than 8 in their final OAB-V8 result were classified as the control group, while a score equal to or greater than 8 meant the participant was placed in the case group. The reduced Yesavage version of the Geriatric Depression Scale (GDS-15) ${ }^{15}$ was used for the identification of depressive symptoms in the sample, while anxiety symptoms were evaluated using the Beck Anxiety Scale (BAS) ${ }^{16}$. 
Interviewers were trained so that each interviewer repeated the question at most three times, if necessary, with no extra explanation during the administration of the questionnaire that might interfere with the participant's interpretation. All the data, from each participant, was collected in a single meeting with an average duration of 30 minutes. Questionnaires were chosen as this strategy provides access to the subjective views of individuals regarding their condition, as well as being an inexpensive and noninvasive method.

The data were analyzed descriptively. Nonnormal distribution of data was confirmed using the Kolmogorov-Smirnov test. The differences in the continuous data of the study subgroups defined according to the presence of overactive bladder as elderly women with versus elderly women without were analyzed using the Mann Whitney $U$ test for independent samples, while the chi-squared test $\left(\mathrm{X}^{2}\right)$ was used for the categorical data. The confidence intervals for the mean of the difference between the continuous data of the groups were calculated.

Binary logistic regression analysis was used to evaluate the significant associations between the independent variables and the outcome of interest (OBS). Firstly, univariate logistic regression analysis was used to determine the association between each independent variable and the dependent variable presence of an overactive bladder, thereby verifying the factors that contributed to the occurrence of this syndrome. The risk ratios (RR) were calculated for each independent (explanatory) variable with 95\% confidence intervals.

Subsequently, the variables that presented an association with a $p$-value lower than 0.20 in univariate regression analysis were included in multivariate logistic regression analysis to investigate the independent effect, when taken together, of these variables, for the explanation of "OBS". The selection of the best model was performed with the reduction of variables procedure, based on the forward stepwise method applying the Likelihood Ratio (LR) criterion, which adds variables based on the significance identified in the statistical scores $(5 \%)$ and removes them from the tests according to the maximum likelihood statistic $(10 \%)$ obtained by the data set. The b-weight value (regression coefficient) associated with each independent variable was used to determine the probability of the elderly having OBS. In multivariate logistic regression, there was no collinearity between the independent (explanatory) variables through the tolerance analysis $(>0.1)$ and the Variance Inflation Factor $(<10)$. A significance level of 5\% was considered.

The present study was approved by the Research Ethics Committee of the Faculdade de Ciências da Saúde (the Health Sciences School) of the Universidade de Brasília (the University of Brasilia), under approval $n^{\circ} 410.161$, dated 30 September 2013, and was carried out from September 2013 to December 2016.

\section{RESULTS}

A total of 372 volunteers were recruited and a total of 292 elderly women were deemed to be eligible, with a total of 172 allocated to the case group and 120 to the control group.

Among the socio-demographic and clinical factors investigated, there was a higher frequency of hypertension and of abdominal and urogynecological surgeries in the case group. The other characteristics were homogeneous.

When the analyzed variables of the groups were compared, there were significant differences in the presence of SAH and having undergone prior abdominal and pelvic surgery, with the case group having higher frequencies of these events. The case group also obtained higher scores in the GDS-15 and BAS questionnaires, with a significant difference between the groups.

Univariate logistic regression analysis showed that BMI, the diagnosis of hypertension, a previous history of abdominal and urogynecological surgery, number of abortions, and higher scores in the GDS15 and BSA questionnaires were associated with OBS when analyzed in an isolated manner, as shown in Table 2. All the other analyzed variables had no association with OBS. 
The ten variables that resulted in a $p$-value lower than 0.20 in univariate analysis were used in multivariate logistic regression analysis. Thus, in the final model, only the diagnosis of diabetes, a history of urogynecological surgery and the maintaining of an active sex life remained as independent variables associated with OBS (Table 3).

Table 1. Comparison of demographic and clinical characteristics of the case group and the control group of elderly women living in the community ( $\mathrm{n}=292)$. Distrito Federal, 2016.

\begin{tabular}{|c|c|c|c|c|c|c|}
\hline \multirow[t]{2}{*}{ Variables } & \multicolumn{2}{|l|}{$\begin{array}{l}\text { Case group } \\
(n=172)\end{array}$} & \multicolumn{2}{|c|}{$\begin{array}{l}\text { Control group } \\
(\mathrm{n}=120)\end{array}$} & \multirow{2}{*}{$\begin{array}{l}\text { Mean difference } \\
{[95 \% \mathrm{CI}]}\end{array}$} & \multirow[t]{2}{*}{$p$-value } \\
\hline & Mean (sd) & $\mathrm{n}(\%)$ & Mean (sd) & $\mathrm{n}(\%)$ & & \\
\hline $\operatorname{Age}^{* *}$ & $68.67(6.12)$ & & $69.71(6.75)$ & & $-1.04(-2.53$ a 0.45$)$ & 0.184 \\
\hline BMI** & $28.07(5.03)$ & & $26.76(4.21)$ & & $1.31(0.21$ a 2.42$)$ & 0.05 \\
\hline Years of schooling** & $1.31(1.00)$ & & $1.36(0.90)$ & & $-0.04(-0.27$ a 0.18$)$ & 0.476 \\
\hline $\begin{array}{l}\text { Skin color/ethnicity*** } \\
\text { White } \\
\text { Black/Afro-Brazilian } \\
\text { Mixed-race } \\
\text { Asian-Brazilian } \\
\text { Other }\end{array}$ & & $\begin{array}{l}56(32.6) \\
18(10.5) \\
23(13.4) \\
22(12.8) \\
53(30.8)\end{array}$ & & $\begin{array}{l}47(39.2) \\
10(8.3) \\
21(17.5) \\
10(8.3) \\
32(26.7)\end{array}$ & & 0.447 \\
\hline $\begin{array}{l}\text { Marital Status*** } \\
\text { Single } \\
\text { Married or cohabiting } \\
\text { Divorced } \\
\text { Widowed }\end{array}$ & & $\begin{array}{l}20(11.6) \\
66(38.4) \\
32(18.6) \\
54(31.4)\end{array}$ & & $\begin{array}{l}17(14.2) \\
45(37.5) \\
20(16.7) \\
38(31.7)\end{array}$ & & 0.913 \\
\hline Gestation** & $5.42(3.69)$ & & $5.45(3.34)$ & & $-0.026(-0.86$ a 0.81$)$ & 0.750 \\
\hline Vaginal deliveries** & $4.15(3.16)$ & & $4.43(3.24)$ & & $-0.27(-1.02$ a 0.47$)$ & 0.432 \\
\hline Cesarean deliveries** & $0.42(0.70)$ & & $0.48(0.73)$ & & $-0.06(-0.23$ a 0.11$)$ & 0.510 \\
\hline Abortions** & $0.85(1.42)$ & & $0.55(0.92)$ & & $0.30(0.03$ a 0.57$)$ & 0.081 \\
\hline Physical activity (yes)*** & & $101(58.7)$ & & $62(51.7)$ & & 0.141 \\
\hline Sexually active(yes) $)^{* * *}$ & & $6(12)$ & & $28(23.3)$ & & 0.067 \\
\hline Smoker (yes) ${ }^{* * *}$ & & $7(4.1)$ & & $5(4.2)$ & & 0.595 \\
\hline Constipation (yes) ${ }^{* * *}$ & & $36(20.9)$ & & $24(20.2)$ & & 0.874 \\
\hline Diabetes (yes) ${ }^{* * *}$ & & $30(17.4)$ & & $29(24.2)$ & & 0.183 \\
\hline $\mathrm{SAH}(\mathrm{yes})^{* * *}$ & & $125(72.7)$ & & $62(51.7)$ & & 0.000 \\
\hline Abdominal surgery (yes)*** & & $127(73.8)$ & & $73(60.8)$ & & 0.013 \\
\hline Urogynecological Surgery(yes)*** & & $77(44.8)$ & & $30(25)$ & & 0.000 \\
\hline GDS-15** & $5.47(2.89)$ & & $4.28(2.81)$ & & $1.18(0.51$ a 1.85$)$ & 0.000 \\
\hline $\mathrm{BAS}^{* *}$ & $17.26(10.54)$ & & $10.51(9.64)$ & & 6.75 (4.36 a 9.13) & 0.000 \\
\hline $\mathrm{OAB}-\mathrm{V} 8^{* *}$ & $22.31(6.49)$ & & $2.61(2.34)$ & & 19.71(18.64 a 20.77) & 0.000 \\
\hline
\end{tabular}


Table 2. Univariate logistic regression to verify factors associated with overactive bladder syndrome. Distrito Federal, 2016.

\begin{tabular}{|c|c|c|c|c|}
\hline \multirow[b]{2}{*}{ Variables } & \multicolumn{3}{|c|}{ Univariate analysis } & \multirow[b]{2}{*}{$p$-value } \\
\hline & b-weights & $\mathrm{RR}$ & $95 \% \mathrm{CI}$ & \\
\hline Age & -0.025 & 0.975 & $0.940-1.011$ & 0.172 \\
\hline Body Mass Index & 0.060 & 1.062 & $1.007-1.121$ & 0.027 \\
\hline Years of schooling & -0.048 & 0.953 & $0.747-1.215$ & 0.696 \\
\hline \multicolumn{5}{|l|}{ Skin color/ethnicity } \\
\hline White & -0.329 & 0.719 & $0.401-1.292$ & 0.270 \\
\hline Black/Afro-Brazilian & 0.083 & 1.087 & $0.447-2.643$ & 0.854 \\
\hline Mixed-race & -0.414 & 0.661 & $0.317-1.381$ & 0.271 \\
\hline Asian-Brazilian & 0.284 & 1.328 & $0.558-3.160$ & 0.521 \\
\hline Other & - & - & - & - \\
\hline Marital Status (lives without spouse) & -0.037 & 0.964 & $0.596-1.558$ & 0.880 \\
\hline Gestation & -0.002 & 0.998 & $0.934-1.066$ & 0.952 \\
\hline Vaginal deliveries & -0.027 & 0.974 & $0.905-1.047$ & 0.471 \\
\hline Cesarean deliveries & -0.115 & 0.891 & $0.644-1.233$ & 0.488 \\
\hline Abortions & 0.217 & 1.242 & $1.001-1.540$ & 0.048 \\
\hline Physical activity (yes) & 0.286 & 1.331 & $0.832-2.128$ & 0.233 \\
\hline Sexually active(yes) & -0.803 & 0.448 & $0.173-1.161$ & 0.098 \\
\hline Smoker (yes) & -0.025 & 0.976 & $0.302-3.150$ & 0.967 \\
\hline Constipation (yes) & -0.047 & 0.954 & $0.535-1.703$ & 0.874 \\
\hline Diabetes (yes) & -0.411 & 0.663 & $0.373-1.177$ & 0.161 \\
\hline Systemic Arterial Hypertension (yes) & 0.911 & 2.488 & $1.523-4.063$ & 0.000 \\
\hline Abdominal surgery (yes) & 0.597 & 1.817 & $1.102-2.996$ & 0.019 \\
\hline Urogynecological Surgery(yes) & 0.889 & 2.432 & $1.459-4.053$ & 0.001 \\
\hline Geriatric depression scale & 0.149 & 1.160 & $1.064-1.266$ & 0.001 \\
\hline Beck anxiety scale & 0.068 & 1.070 & $1.042-1.098$ & 0.000 \\
\hline
\end{tabular}

$\mathrm{RR}=$ risk ratios; $\mathrm{CI}=$ Confidence interval.

Tabela 3. Univariate logistic regression to verify factors associated with overactive bladder syndrome. Distrito Federal, 2016.

\begin{tabular}{lllll}
\hline \multirow{2}{*}{ Variables } & \multicolumn{2}{l}{ Multivariate analysis } & & \\
& b-weights & RR & $95 \%$ CI & $p$-value \\
\hline Age & -0.038 & 0.963 & $0.900-1.030$ & 0.267 \\
\hline Body Mass Index & 0.057 & 1.059 & $0.972-1.152$ & 0.189 \\
\hline Abortions & 0.200 & 1.221 & $0.861-1.731$ & 0.262 \\
\hline Sexually active(yes) & -1.233 & 0.292 & $0.089-0.954$ & 0.041 \\
\hline Diabetes (yes) & -1.057 & 0.348 & $0.122-0.993$ & 0.048 \\
\hline Systemic Arterial Hypertension (yes) & 0.737 & 2.090 & $0.824-5.300$ & 0.120 \\
\hline Abdominal surgery (yes) & 0.623 & 1.864 & $0.751-4.628$ & 0.179 \\
\hline Urogynecological Surgery(yes) & 1.131 & 3.098 & $1.372-6.999$ & 0.007 \\
\hline Geriatric depression scale & 0.089 & 1.094 & $0.932-1.282$ & 0.271 \\
\hline Beck anxiety scale & 0.045 & 1.046 & $1.000-1.094$ & 0.050 \\
\hline
\end{tabular}

$\mathrm{RR}=$ risk ratios; $\mathrm{CI}=$ Confidence Interval. 
These results indicate that maintaining an active sex life and the diagnosis of diabetes reduce the odds of having OBS by $70.8 \%$ and $65.2 \%$, respectively, while a history of urogynecologic surgery increases the risk of OBS 3.098 times.

\section{DISCUSSION}

The present study identified a high prevalence of OBS among elderly women in the community studied (58.9\%), a finding similar to other studies ${ }^{17-19}$. The risk factors assessed were: age; BMI; parity (gestations, vaginal deliveries, cesarean deliveries and abortions), schooling, previous abdominal and urogynecologic surgeries, physical activity, smoking, hypertension, depression, anxiety, diabetes mellitus and constipation.

The present study found that individuals in the case group had a higher BMI than those in control group, although this difference was not significant $(p=0.05)$. Many studies have reported that high $\mathrm{BMI}$ is a factor associated with $\mathrm{OBS}^{12,18}$. Brown et al. ${ }^{20}$ affirmed that obesity is directly associated with UI and urinary symptoms such as micturition urgency, polyuria and nocturia, a fact that has also been observed by other authors ${ }^{21,22}$. In the present study, however, no significant difference in BMI was found when the group of elderly women with OBS and those without OBS were compared, although univariate logistic regression analysis identified an association between BMI and OBS when considered separately. The relationship between OBS and BMI is not well defined in literature, as authors such as Oliveira et al. ${ }^{9}$ and Cheung et al. ${ }^{23}$ did not observe such an association, and so further studies on the subject are required.

The diagnosis of $\mathrm{SAH}$ was more frequent among elderly women in the case group of the present study, and univariate logistic regression analysis indicated that this diagnosis was a factor associated with OBS. The same was observed in a study of 1,410 men and 1,546 women aged over 65 in Japan by Hirayama et al. ${ }^{11}$, in which the diagnosis of SAH was equally and significantly greater in individuals with symptoms of OBS. Ekundayo ${ }^{24}$ performed a review considering the presence of OBS in hypertensive patients and observed that there was an association between the use of diuretics and increased urinary frequency and urgency, but not with UI. These authors stated that alterations in micturition may be related to treatments for hypertension, as antihypertensive medications and diuretics increase urine output, which exacerbates symptoms in patients with voiding dysfunction. Reis et al. ${ }^{25}$ cite in their study that some medications, including diuretics and other medicines used in the treatment of hypertension, are possible causes of UI in the elderly. However, Jardim et al. ${ }^{26}$ performed an integrative review of SAH and UI among the elderly and found no evidence of the relationship between the two conditions.

The case group in the present study scored higher in the GDS questionnaire, which suggests that this group may have more depressive symptoms than the control group. This result was also observed by other authors, such as Ikeda et al. ${ }^{18}$, in a study of 414 elderly men and 419 elderly women in Japan, the objective of which was to measure the prevalence of risk factors for OBS in elderly persons with questionnaires. The authors described a mean OBS prevalence of $17.6 \%$ in men and $19.1 \%$ in women, and stated that the risk for developing OBS was significantly higher in individuals with depressive symptoms and alcoholic habits and who were overweight. Alves et al. ${ }^{6}$, conducted a study in Brazil with 161 elderly women that evaluated the association between OBS and depression. The authors observed a high prevalence of OBS (76.3\%), with $42.6 \%$ of sufferers presenting mild or severe depression, revealing a significant correlation between OBS and depression.

Hirayama et al. ${ }^{11}$ conducted a similar study in Japan with 1,410 men and 1,546 women. Its objective was to evaluate the incidence and remission rate of OBS and its risk factors for new cases among the elderly. The authors observed that the incidence and remission rates in one year were $11.9 \%$ and $29.8 \%$, respectively. They also observed a relationship between urinary symptoms and alcohol consumption and smoking, hypertension, and a depressive state in individuals with recent-onset $\mathrm{OBS}$, all of which were significantly higher than in individuals without OBS.

When the BAS results of the groups were compared, the mean overall score of the case group was higher, suggesting a higher level of anxiety. This result is consistent with those described in the literature. Studies have shown that anxiety symptoms are common among the elderly and in 
the majority of patients with symptoms of $\mathrm{OBS}^{27,28}$. Knight et al. ${ }^{28}$ carried out a study comparing the electromyography of the pelvic floor muscles of women with OBS symptoms and the BAS score of women without urinary complaints. Although the authors reported no difference in electromyography between the groups, the group with symptoms of OBS had significantly higher anxiety scores.

Lai et al. ${ }^{27}$ studied the relationship between anxiety and OBS. These authors observed that $48 \%$ of individuals with symptoms of OBS also had symptoms of anxiety, with $24 \%$ of these suffering from moderate to severe anxiety. The authors state that the anxiety scores of individuals with OBS were significantly higher than the control results. Alves et al. ${ }^{21}$ also investigated this relationship, and observed a correlation between anxiety and OBS $(r=0,345)$.

The elderly women in the case group presented significant differences in terms of prior history of abdominal and urogynecologic surgery and abortions, and these variables were presented as factors associated with OBS when analyzed in isolation. This relationship is not yet fully clarified in literature, with few studies specifically addressing these issues. Additional studies with long-term follow up periods are therefore required to prove such results.

In terms of surgeries, the multivariate analysis of the present study found that those who underwent urogynecological surgeries had a 3.098 greater chance of OBS. Abraham and Vasavada ${ }^{29}$ performed a review on urgency after sling surgery. The authors reported an estimated $40 \%$ post-operative urgency rate, which may be due to urinary tract infection (7.4-17.4\%), bladder outlet obstruction (1.9-19.7\%), urinary tract perforation (0.5-5\%) and/or idiopathic urgency (0$28 \%$ ). Duru et al. ${ }^{30}$ performed a systematic review in order to analyze urodynamic outcomes before and after a total hysterectomy for benign conditions and to report whether urinary function was altered after the hysterectomy. The authors observed that the urodynamic diagnosis of detrusor overactivity and UI symptoms were significantly reduced after a hysterectomy. The authors therefore concluded that a hysterectomy does not adversely affect urodynamic outcomes, nor does it increase the risk of adverse urinary symptoms, and may even improve some urinary functions.
While it was observed in the present study that maintaining an active sex life reduces the chance of developing OBS, no articles were found in literature to prove this finding, making it an excellent topic for future research. It is possible to find works such as that of Coyne et al. ${ }^{31}$, a cross-sectional study that evaluated the symptoms of OBS and the sexual activity of men and women through internet questionnaires in the United Kingdom, Sweden and the USA. The authors observed worse sexual health in individuals with OBS in comparison with those who did not suffer from the condition and warned about the importance of assessing the sexual health of men and women with OBS.

Chen et al. ${ }^{32}$ carried out a literature review that observed the relationship between urinary symptoms and female sexual dysfunction. The authors noted that sexual and urinary problems are often comorbid and have been associated with a wide range of sexual response deficiencies, including declines in desire, arousal, lubrication, orgasm, general sexual satisfaction and increased sexual pain, when compared with women without urinary symptoms. The authors stated that paying attention to urinary problems can improve women's sexual quality of life.

In this study, having diabetes was shown as a protective factor for OBS, a fact that contradicts results found in literature, such as those of the studies of Wen et al. ${ }^{12}$ and Ikeda et al. ${ }^{10}$. Wen et al. ${ }^{12}$ evaluated the prevalence of risk factors associated with OBS in China with 3,129 men and 6,676 women aged over 40 years. They observed that prevalence increased with age in both sexes, and was also higher in individuals with diabetes and with a BMI above 29. Likewise, a study carried out in Japan by Ikeda et al. ${ }^{10}$, involved the application of questionnaires on the presence of OBS symptoms in 652 diabetic patients and identified a prevalence of cases of $24.2 \%$ in the study population. The authors stated that this prevalence was twice as high as that of the general Japanese population. These results indicate the need to carry out further studies with larger and more representative samples.

A potential limitation of this work is difficulty in finding studies that refer to factors associated with OBS that mainly involve elderly women. This is an incentive for further research as there are still many 
issues to be addressed. Another limiting factor was the large number of exclusions due to missing data in the questionnaires, which limited the sample.

One probable bias that should be considered in the present study is the use of questionnaires through interview. While questionnaires are important tools in data collection, both for diagnosis and for epidemiological studies, there is no consensus on how best to use them. It is not possible to predict how the patient understands/perceives the questions or how they will respond. Thus, the routine used during the completion of this instrument directly affects the quality of the data collected. Bowling ${ }^{33}$, after conducting a systematic review, stated that different ways of applying questionnaires affect the quality of the data collected. This author affirms that there is no gold standard for the use of this instrument and that all forms have advantages and biases. However, despite the possibility of bias in the method employed, it is unlikely that the use of another technique could have significantly altered the quality or results presented here.

\section{CONCLUSION}

The present study identified urogynecologic surgery as a factor associated with overactive bladder syndrome. In contrast, a diagnosis of diabetes and maintaining an active sex life were protective factors in elderly women in the community studied. However, additional studies are needed to prove these results.

Overactive bladder syndrome should be considered a public health problem as it is highly prevalent among elderly women. It is therefore necessary to elaborate new care strategies and actions of prevention and health promotion that contribute to healthier aging and quality of life.

\section{REFERENCES}

1. Haylen BT, Freeman RM, Swift SE, Cosson M, Davila GW, Deprest J, et al. An International Urogynecological Association (IUGA)/International Continence Society (ICS) joint terminology and classification of the complications related directly to the insertion of prostheses (meshes, implants, tapes) and grafts in female pelvic floor surgery. Neurourol Urodyn [Internet]. 2011 [acesso em 20 jun. 2016];30(1):2-12. Disponível em: https://www.ncbi. nlm.nih.gov/pubmed/21531195

2. Bartoli S, Aguzzi G, Tarricone R. Impact on Quality of Life of Urinary Incontinence and Overactive Bladder: a Systematic Literature Review. Urology. 2010;75(3):491-500.

3. Coyne KS, Sexton CC, Kopp ZS, Ebel-Bitoun C, Milsom I, Chapple C. The impact of overactive bladder on mental health, work productivity and health-related quality of life in the UK and Sweden: results from EpiLUTS. BJU Int. 2011;108(9):1459-71.

4. Milsom I, Coyne KS, Nicholson S, Kvasz M, Chen CI, Wein AJ. Global prevalence and economic burden of urgency urinary incontinence: a systematic review. Eur Urol [Internet]. 2014 [acesso em 22 jun. 2016];65(1):79-95. Disponível em: https://www.ncbi. nlm.nih.gov/pubmed/24007713

5. Kwon BE, Kim GY, Son YJ, Roh YS, You MA. Quality of life of women with urinary incontinence: a systematic literature review. Int Neurourol J. 2010;14(3):133-8.

6. Alves AT, Jácomo RH, Silva RCM, Gomide LB, Bontempo APS, Garcia PA. Association between overactive bladder syndrome and depression among older women. Top Geriatr Rehabil [Internet]. 2016 [acesso em 02 jan. 2017];32(4):25863. Disponível em: http://journals.lww.com/ topicsingeriatricrehabilitation/Abstract/2016/10000/ Association_Between_Overactive_Bladder_ Syndrome.5.aspx

7. Irwin D, Kopp Z, Agatep B, Milsom I, Abrams P. Worldwide prevalence estimates of lower urinary tract symptoms, overactive bladder, urinary incontinence and bladder outlet obstruction. BJU Int [Internet]. 2011 [acesso em 22 jun. 2016];108(7):1132-9. Disponível em: https://www. ncbi.nlm.nih.gov/pubmed/21231991

8. Moroni RM, Magnani PS, Rodrigues HLP, Barrilari SEG, Dos Reis FJC, Brito LGO. Treatment of idiopathic refractory overactive bladder syndrome. Feminina. 2013;41(3):147-54. 
9. Oliveira E, Zuliani LMM, Ishicava J, Silva SV, Albuquerque SSR, De Souza AMB, et al. Avaliação dos fatores relacionados à ocorrência da incontinência urinária feminina. Rev Assoc Med Bras. 2010;56(6):688-90.

10. Ikeda M, Nozawa K. Prevalence of overactive bladder and its related factors in Japanese patients with diabetes mellitus. Endocr J [Internet]. 2015 [acesso em 20 jun. 2016];62(9):847-54. Disponível em: https:// www.ncbi.nlm.nih.gov/pubmed/26166691

11. Hirayama A, Torimoto K, Mastusita C, Okamoto N, Morikawa M, Tanaka N, et al. Risk factors for newonset overactive bladder in older subjects: Results of the Fujiwara-kyo study. Urology. 2012;80(1):71-6.

12. Wen JG, Li JS, Wang ZM, Huang CX, Shang XP, Su $\mathrm{ZQ}$, et al. The prevalence and risk factors of $\mathrm{OAB}$ in middle-aged and old people in China. Neurourol Urodyn. 2014;33(4):387-91.

13. Instituto Brasileiro de Geografia e Estatística. Censo Demográfico 2000 - Características Gerais da População. Resultados da Amostra [Internet]. Rio de Janeiro: IBGE; 2010 [acesso em 15 out. 2015]. Disponível em http://censo2010.ibge.gov.br/apps/atlas/

14. Acquadro C, Kopp Z, Coyne KS, Corcos J, Tubaro A, Choo MS. Translating overactive bladder questionnaires in 14 languages. Urology. 2006;67(3):536-40.

15. Almeida OP, Almeida SA. Reliability of the Brazilian version of the geriatric depression scale (GDS) short form. Arq Neuropsiquiatr. 1999;57(2 B):421-6.

16. Wolitzky-Taylor KB, Castriotta N, Lenze EJ, Stanley MA, Craske MG. Anxiety disorders in older adults: a comprehensive review. Depress Anxiety. 2010;27(2):190-211.

17. Franco MDM, Souza FDO, Cristine E, Mateus L. Avaliação da qualidade de vida e da perda urinária de mulheres com bexiga hiperativa tratadas com eletroestimulação transvaginal ou do nervo tibial. Fisioter Pesqui. 2011;18(2):145-50.

18. Ikeda Y, Nakagawa H, Ohmori-Matsuda K, Hozawa A, Masamune Y, Nishino Y, et al. Risk factors for overactive bladder in the elderly population: a community-based study with face-to-face interview. Int J Urol. 2011;18(3):212-8.

19. Coyne KS, Margolis MK, Kopp ZS, Kaplan SA. Racial differences in the prevalence of overactive bladder in the United States from the Epidemiology of LUTS (EpiLUTS) study. Urology [Internet]. 2012 [acesso em 20 jun. 2016];79(1):95101. Disponível em: https://www.ncbi.nlm.nih. gov/pubmed/22055692
20. Brown JS, Seeley DG, Fong J, Black DM, Ensrud KE, Grady D. Urinary incontinence in older women: who is at risk? Study of Osteoporotic Fractures Research Group. Obstet Gynecol [Internet]. 1996 [acesso em 20 jun. 2016];87(5 Pt 1):715-21. Disponível em: https:// www.ncbi.nlm.nih.gov/pubmed/?term=Urinary+incon tinence + in + older + women $\% 3 \mathrm{~A}+$ who + is + at + risk $\% 3 \mathrm{~F}+$ Study+of+Osteoporotic+Fractures+Research+Group

21. Alves AT, Jácomo RH, Gomide LB, Garcia PA, Bontempo APS, Karnikoskwi MGO. Relationship between anxiety and overactive bladder syndrome in older women. Rev Bras Ginecol Obstet [Internet]. 2014 [acesso em 03 jul. 2016];36(7):310-4. Disponível em: http://www.scielo.br/scielo.php?script=sci_arttex t\&pid=S0100-72032014000700310

22. Siegel S, Noblett K, Mangel J, Giebling T, Sutherland SE, Bird ET. Results of a prospective, randomized, multicenter study evaluating sacral neuromodulation with Interstim therapy compared to standard medical therapy at 6 monts in subjects with mild symptoms of overactive bladder. Neurourol Urodyn. 2015;34(3):224-30.

23. Cheung WW, Blank W, Borawski D, Tran W, Bluth $\mathrm{MH}$. Prevalence of overactive bladder, its underdiagnosis, and risk factors in a male urologic veterans population. Int J Med Sci. 2010;7(6):391-4.

24. Ekundayo OJ. The association between overactive bladder and diuretic use in the elderly. Curr Urol Rep. 2009;10(6):434-40.

25. Dos Reis RB, Cologna AJ, Martins ACP, Paschoalin EL, Tucci Jr S, Suaid HJ. Incontinência urinária no idoso. Acta Cir Bras. 2003;18(Supl 5):47-51.

26. Jardim ADI, Mazzo A, Girão FB, Sonobe HM, Souza MC. Hipertensão arterial e incontinência urinária no idoso: revisão integrativa da literatura. Cuid Enferm. 2011;5(1):38-43.

27. Lai HH, Rawal A, Shen B, Vetter J. The Relationship Between Anxiety and Overactive Bladder or Urinary Incontinence Symptoms in the Clinical Population. Urology [Internet]. 2016 [acesso em 15 ago. 2016];98:50-7 Disponível em:. https://www.ncbi.nlm. nih.gov/pubmed/27450939

28. Knight S, Luft J, Nakagawa S, Katzman WB. Comparisons of pelvic floor muscle performance, anxiety, quality of life and life stress in women with dry overactive bladder compared with asymptomatic women. BJU Int. 2012;109(11):1685-9.

29. Abraham N, Vasavada S. Urgency After a Sling: Review of the Management [abstract]. Curr Urol Rep [Internet]. 2014 [acesso em 15 ago. 2016];15(4):400. Disponível em: https://www.ncbi.nlm.nih.gov/ pubmed/24515329 
30. Duru C, Jha S, Lashen H. Urodynamic Outcomes After Hysterectomy for Benign Conditions. Obstet Gynecol Surv. [Internet]. 2012 [acesso em 10 ago. 2016];67(1):45-54. Disponível em: https://www.ncbi. nlm.nih.gov/pubmed/22278078

31. Coyne KS, Sexton CC, Thompson C, Kopp ZS, Milsom I, Kaplan SA. The impact of OAB on sexual health in men and women: results from EpiLUTS. J Sex Med [Internet]. 2011 [acesso em 20 jun. 2016];8(6):1603-15. Disponível em: https://www.ncbi. nlm.nih.gov/pubmed/21492396
32. Chen J, Sweet G, Shindel A. Urinary disorders and female sexual function. Curr Urol Rep. 2013;14(4):298-308.

33. Bowling A. Mode of questionnaire administration can have serious effects on data quality. J Public Health. 2005;27(3):281-91.

Received: March 07, 2017

Reviewed: April 21, 2017

Accepted: July 06, 2017 